ORIGINAL ARTICLE

\title{
No association between the use of cellular or cordless telephones and salivary gland tumours
}

\author{
L Hardell, A Hallquist, K Hansson Mild, M Carlberg, H Gertzén, E-B Schildt, Å Dahlqvist
}

See end of article for

Occup Environ Med 2004;61:675-679. doi: 10.1136/oem.2003.011262

authors' affiliations

.....................

Correspondence to: Dr L Hardell, Department of Oncology, University Hospital, SE-701 85 Örebro and Department of Natural Sciences, Örebro University, SE-701 82 Örebro, Sweden; lennart. hardell@orebroll.se

Accepted

14 February 2004

\begin{abstract}
Aim: To investigate the association between the use of cellular or cordless telephones and the risk for salivary gland tumours.

Methods: Cases were assessed from the six regional cancer registries in Sweden. Four controls matched for sex and age in five year age groups were selected for each case. A total of 293 living cases and 1172 controls were included.

Results: There were 267 (91\%) participating cases and 1053 (90\%) controls. Overall no significantly increased risk was found. Odds ratios were $0.92(95 \% \mathrm{Cl} 0.58$ to 1.44$)$ for use of analogue phones, 1.01 (95\% Cl 0.68 to 1.50$)$ for use of digital phones, and 0.99 (95\% $\mathrm{Cl} 0.68$ to 1.43 ) for use of cordless phones. Similar results were found for different salivary gland localisations. No effect of tumour induction period or latency was seen, although few subjects reported use for more than 10 years.

Conclusions: No association between the use of cellular or cordless phones and salivary gland tumours was found, although this study does not permit conclusions for long term heavy use.
\end{abstract}

$\mathrm{R}$ ecently we published results from a large case-control study on the use of cellular and cordless telephones and the risk for brain tumours. ${ }^{1-5}$ In summary we found a significantly increased risk for use of analogue cellular telephones, with the highest risk for tumours located in the most exposed part of the brain. Different phones result in different anatomical distribution of the specific absorption rate of the microwaves, ${ }^{67}$ and since the parotid gland is located in an area where some phones give a high exposure to microwaves, it is appropriate to also study this tumour type.

During cellular phone calls microwaves are transmitted and received in the range 400-2000 MHz. In Sweden the analogue system (Nordic Mobile Telephone System; NMT) was introduced in 1981, operating at $450 \mathrm{MHz}$, often in a car with fixed external antenna; from 1984 the first portable analogue phones were available. The analogue $900 \mathrm{MHz}$ system operated in Sweden between 1986 and 2000. The digital system (Global System for Mobile Communication; GSM) started in 1991 and has been the most common phone system in use since the end of the 1990s in Sweden. Furthermore, desktop cordless telephones have been used in Sweden since 1988. Initially the analogue system in the 800-900 MHz RF range was used, but digital cordless telephones that operate at $1900 \mathrm{MHz}$ are now available.

Salivary gland tumours are rare and constituted only $0.2 \%$ of all tumours reported to the Swedish cancer register in 2001. ${ }^{8}$ Both benign and malignant tumours have been reported, and a total of 90 cases were registered in 2000. About $90 \%$ of the tumours are located in the parotid gland. Salivary gland tissue is also present in a number of other sites, such as the lips, gum, floor of mouth, hard and soft palate, tonsillar region, tongue, and lacrimal gland. In all these different localisations both inflammatory and neoplastic lesions may occur.

Ionising radiation is one risk factor for salivary gland tumours. ${ }^{9}$ Medical radiation treatment of the head or neck, full mouth dental $x$ rays, and ultraviolet light treatment to the head and neck have been associated with salivary gland cancer. ${ }^{10}$ Work in the rubber industry has been described as one risk factor, ${ }^{10}$ but salivary gland tumours are usually not regarded as occupational diseases. Smoking is not regarded as a risk factor.
Regarding cellular phones and the risk for salivary gland tumours, a Finnish study reported an odds ratio (OR) of 1.3 (95\% CI 0.4 to 4.7 ) for those who had ever had a cellular phone subscription. ${ }^{11}$ However, use of cordless phones was not assessed in that study. A Danish study on subscribers of cellular telephones found seven salivary gland tumours versus nine expected. ${ }^{12}$ However, inflammatory changes in the parotid gland associated with microwave exposure have been reported. ${ }^{13}$

\section{METHODS}

The geographical study area was the whole of Sweden. All local ethical committees in the different geographical study areas approved the study. The cases were reported from the regional cancer registries. Due to local circumstances such as inclusion of the patients in other studies, the recruitment period for patients differed in the various medical regions of Sweden. Thus, patients were included from the Stockholm and Linköping medical regions during 1 January 1994 to 31 December 1999, Uppsala-Örebro during l January 1994 to 30 June 2000, and for the rest of Sweden (the Umeå, Göteborg, and Lund medical regions) during 1 January 1994 to 30 June 1999. The physicians were contacted for permission to include patients in the study. Only living cases were finally included in the study in order to obtain as high a quality in assessment of exposure as possible.

The study was performed during the same time period as our study on brain tumours. ${ }^{1-4}$ Furthermore, the geographical area was similar same in both studies-that is, Stockholm, Uppsala-Örebro, Linköping, and Göteborg medical areas. Additionally patients were recruited from Umeå and Lund medical regions in this study. Four controls were used for each case matched for sex and age in five year groups. In the overlapping geographical area, controls $(n=815)$ were selected at random from those originally drawn for the brain tumour study; additionally 89 controls were selected from the population register when the matching criteria were not fulfilled in the brain tumour control group. From all other

Abbreviations: $\mathrm{Cl}$, confidence interval; GSM, Global System for Mobile Communication; $\mathrm{MHz}$, mega Hertz; NMT, Nordic Mobile Telephone System; OR, odds ratio; RF, radiofrequency 


\section{Main messages}

- The anatomical localisation of the parotid gland is in an area with exposure to microwaves from cellular and cordless telephones.

- A case-control study was performed to investigate a potential association. No significantly increased risk was found.

parts of Sweden (Umeå and Lund medical regions) controls were drawn from the Swedish national population register. Matching for age was done in five year age groups and the controls were selected at random from this age group. Controls were selected at the same time as cases. Each study subject received a unique ID number which did not indicate whether it was a case or control.

\section{Assessment of exposure}

Exposures were assessed using the same questionnaire as in our brain tumour study. ${ }^{1-4} \mathrm{~A}$ trained nurse checked and supplemented the answers over the phone using a written protocol. All subjects were called in order to obtain data of as high a quality as possible, as in our brain tumour study. ${ }^{1}$ Thus, the study protocol was identical to that in the brain tumour study.

For cellular telephones questions were asked on type of phone and years of use. Also the first part of the phone number (prefix) was asked for to check if it was an analogue (010) or digital (070) phone. Mean number of daily calls and minutes were asked for and cumulative use in hours for all years was calculated. Data were also collected on use in a car with fixed external antenna or a hands-free device with an earpiece outside a car, both taken as no exposure to microwaves. In one question the ear most frequently used during cellular phone calls was asked for, or if both sides were equally used.

Regarding cordless phones the years of use, mean number of minutes per day, and ear used were asked for.

Subjects that started their use of a mobile or cordless phone within one year prior to diagnosis were regarded as unexposed. The same year was used for the matched control as for the corresponding case. Cumulative exposure was calculated in hours from the first year of use up to the year before diagnosis. If the first year was apparently incorrect - that is, before the phone used was on the market,

\section{Policy implications}

- The results of this study did not show that users of cellular or cordless telephones have an increased risk for salivary gland tumours.

this was corrected during the interviews and coding of exposure.

Histopathology results were obtained from the cancer registry. Information on tumour localisation was also available for many cases in the cancer registry report, otherwise from medical records after informed consent from the cases. All coding of anatomical area of the tumour and exposure was done without knowing whether the subject was exposed to cellular or cordless phones.

\section{Statistical methods}

Unconditional logistic regression analysis was used to calculate odds ratios (OR) and 95\% confidence intervals (CI) (SAS Institute, Cary, NC). The material was divided into two groups: exposed and unexposed. The exposed cases and controls were further divided according to phone type: analogue, digital, and cordless. A person may have been using more than one type of telephone. The unexposed group consisted of cases and controls without exposure to either cellular or cordless telephones. Adjustment was made for age and sex. In one analysis adjustment was also made for study area-that is, the geographical area as in the brain tumour study or the rest of Sweden, but this did not significantly change the results (data not presented). In the calculations of laterality of exposure, the corresponding control was assigned the same anatomical localisation as for the respective case.

\section{RESULTS}

In total 415 cases were reported from the regional cancer registries. Of these, 96 had died, 15 were excluded since the treating physician considered them not to be eligible, eight were excluded because of wrong diagnosis, and three were not able to participate due to severe disease. Thus a total of 293 cases were included. The questionnaire was answered by 267 (91\%) of the cases. For the controls, 815 were selected at random from the initial control group in our study on brain tumours. Of these, 750 (92\%) participated. Additionally 357 controls were drawn from the population registry for the remaining part of the country (see above), and 303 (85\%) of

Table 1 Odds ratios and $95 \%$ confidence intervals for use of cellular or cordless telephones

\begin{tabular}{|c|c|c|c|c|c|c|c|c|c|}
\hline & \multicolumn{3}{|c|}{$>1$ year latency } & \multicolumn{3}{|c|}{$>5$ year latency } & \multicolumn{3}{|c|}{$>10$ year latency } \\
\hline & $\mathrm{Ca} / \mathrm{Co}_{\mathrm{O}}$ & OR & $95 \% \mathrm{Cl}$ & $\mathrm{Ca} / \mathrm{Co}_{\mathrm{o}}$ & OR & $95 \% \mathrm{Cl}$ & $\mathrm{Ca} / \mathrm{Co}$ & OR & $95 \% \mathrm{Cl}$ \\
\hline \multicolumn{10}{|l|}{ Analogue } \\
\hline $450 \mathrm{MHz}$ & $14 / 67$ & 0.85 & 0.46 to 1.57 & $11 / 49$ & 0.92 & 0.46 to 1.83 & $5 / 28$ & 0.74 & 0.28 to 1.98 \\
\hline $900 \mathrm{MHz}$ & $22 / 94$ & 0.99 & 0.58 to 1.67 & $9 / 58$ & 0.65 & 0.31 to 1.36 & $1 / 9$ & 0.47 & 0.06 to 3.74 \\
\hline All & $31 / 137$ & 0.92 & 0.58 to 1.44 & $17 / 88$ & 0.78 & 0.44 to 1.38 & $6 / 35$ & 0.71 & 0.29 to 1.74 \\
\hline$\leqslant 91 \mathrm{~h}$ & $16 / 69$ & 0.94 & 0.52 to 1.68 & $7 / 36$ & 0.79 & 0.34 to 1.82 & $2 / 10$ & 0.83 & 0.18 to 3.89 \\
\hline$>91 \mathrm{~h}$ & $15 / 68$ & 0.90 & 0.49 to 1.66 & $10 / 52$ & 0.78 & 0.38 to 1.61 & $4 / 25$ & 0.66 & 0.22 to 1.95 \\
\hline Digital & $45 / 170$ & 1.01 & 0.68 to 1.50 & $8 / 27$ & 1.22 & 0.54 to 2.78 & - & - & - \\
\hline$\leqslant 64 \mathrm{~h}$ & $22 / 89$ & 0.96 & 0.58 to 1.59 & $2 / 7$ & 1.16 & 0.24 to 5.63 & - & - & - \\
\hline$>64 \mathrm{~h}$ & $23 / 81$ & 1.07 & 0.64 to 1.80 & $6 / 20$ & 1.25 & 0.48 to 3.21 & - & - & - \\
\hline Cordless & $48 / 200$ & 0.99 & 0.68 to 1.43 & $18 / 66$ & 1.15 & 0.65 to 2.03 & $0 / 5$ & - & - \\
\hline$\leqslant 183 \mathrm{~h}$ & $27 / 103$ & 1.07 & 0.67 to 1.71 & $6 / 25$ & 1.01 & 0.40 to 2.53 & $0 / 1$ & - & - \\
\hline$>183 \mathrm{~h}$ & $21 / 97$ & 0.89 & 0.53 to 1.50 & $12 / 41$ & 1.24 & 0.62 to 2.44 & $0 / 4$ & - & - \\
\hline All & $91 / 352$ & 1.02 & 0.75 to 1.38 & $32 / 145$ & 0.90 & 0.58 to 1.39 & $6 / 38$ & 0.65 & 0.27 to 1.59 \\
\hline$\leqslant 182 \mathrm{~h}$ & $49 / 177$ & 1.09 & 0.75 to 1.57 & $11 / 45$ & 0.98 & 0.49 to 1.97 & $2 / 7$ & 1.17 & 0.24 to 5.71 \\
\hline$>182 \mathrm{~h}$ & $42 / 175$ & 0.94 & 0.63 to 1.39 & $21 / 100$ & 0.86 & 0.51 to 1.44 & $4 / 31$ & 0.53 & 0.18 to 1.55 \\
\hline
\end{tabular}

Number of exposed cases $(\mathrm{Ca})$ and controls $(\mathrm{Co})$ is given. Dose-effect calculations were made with median number of hours for controls as cut-off. Unconditional logistic regression adjusted for age and sex. Unexposed group consisted of cases and controls with no exposure to cellular or cordless phones. 

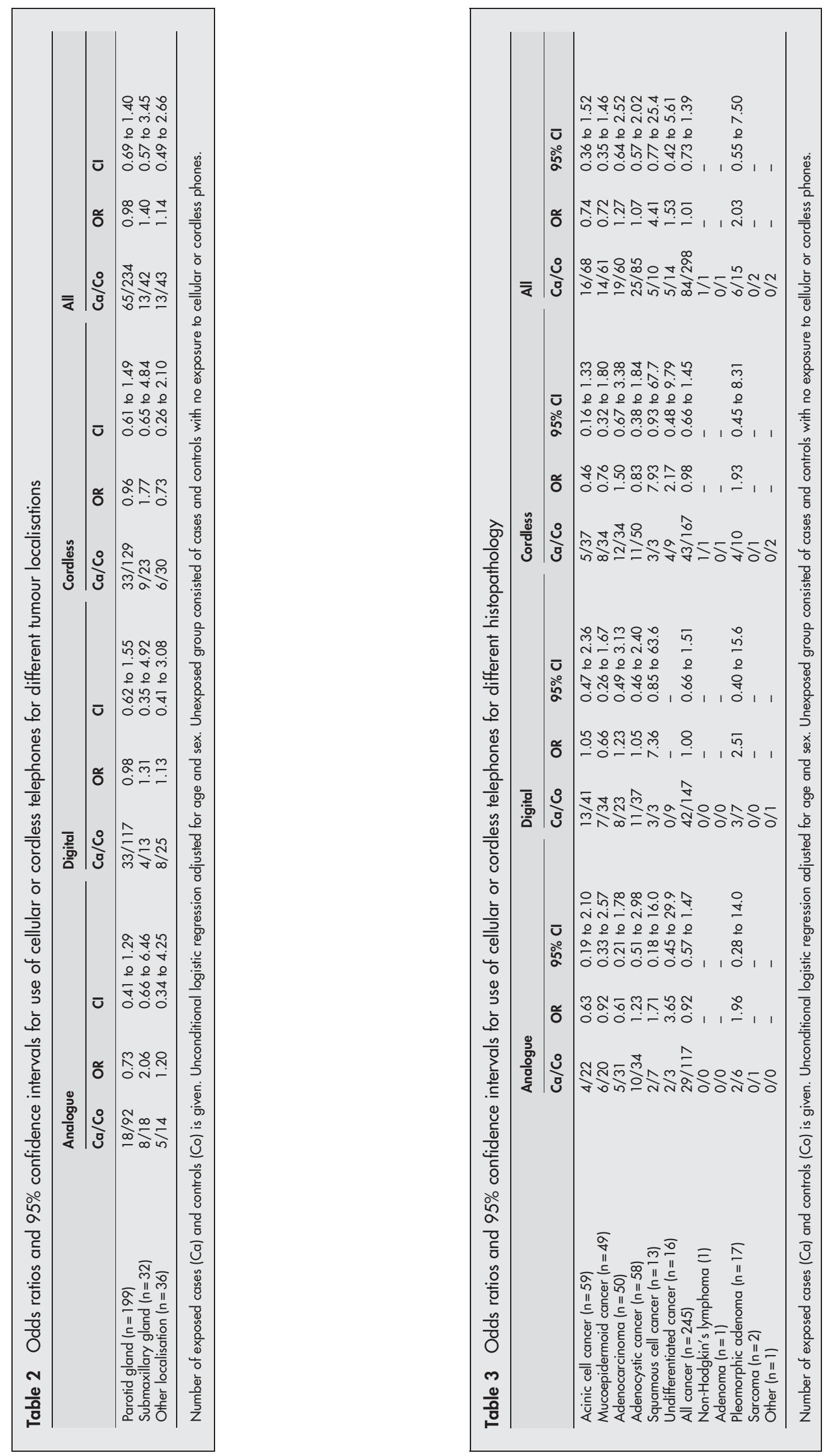

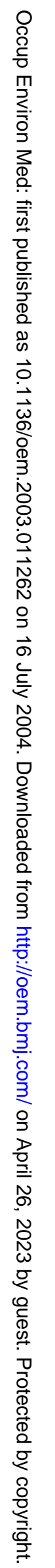


these answered the questionnaire. Thus, the results were based on replies from 267 cases and 1053 (90\%) controls.

The median age for both controls and cases was 59 years (range 21-80). Of the cases, $136(50.9 \%)$ were men and 131 (49.1\%) women, compared with $532(50.5 \%)$ and 521 (49.5\%), respectively, of the controls. For the cases the median number of years for use of analogue phones was six, digital telephones three, and cordless phones five.

Ever use of analogue phones was reported by 31 cases ( $11.6 \%)$ and 137 controls (13.0\%), digital phones by 45 cases (16.9\%) and 170 controls (16.1\%), and cordless phones by 48 cases $(18.0 \%)$ and 200 controls (19.0\%). Ever use of cellular and/or cordless phones was reported by 91 cases $(34.1 \%)$ and 352 controls $(33.4 \%)$.

Overall no association was found between cellular or cordless phones and salivary gland tumours (table 1). The odds ratio for use of analogue phones was 0.92 (95\% CI 0.58 to 1.44 ), for use of digital phones was 1.01 (95\% CI 0.68 to 1.50 ), and for use of cordless phones was 0.99 (95\% CI 0.68 to 1.43). No significant change in the results was found when latency (tumour induction) period or dose-response by cumulative use was analysed with the median number of total hours for the controls used as cut off point (see table 1). The OR for all use, that is analogue, digital, and/or cordless phones was 1.02 (95\% CI 0.75 to 1.38 ), with no effect of latency period or cumulative use in hours. Furthermore, no consistent pattern of increased risk was found according to laterality of the tumour and ear used during phone calls (data not shown).

Table 2 presents results for different anatomical localisations. Tumours in the parotid gland constituted the majority. No increased risk was found for that localisation. An increased risk was found for all studied phone types or tumours in the submaxillary gland. However, these results were based on low numbers of cases.

Table 3 presents histopathology types of the different salivary gland tumours. For squamous cell cancer an increased risk was found for analogue, digital, and cordless telephone types. When all telephone types were analysed together, OR was 4.41 (95\% CI 0.77 to 25.4 ). However, squamous cell cancer constituted only 13 cases of 267 in total. The increased risk for cordless phones (OR 7.93, 95\% CI 0.93 to 67.7) was based on only three exposed cases. The ORs for all cancer (excluding benign tumours) were 0.92 (95\% CI 0.57 to 1.47 ) for analogue phones, 1.00 (95\% CI 0.66 to 1.51 ) for digital phones, and 0.98 (95\% CI 0.66 to 1.45 ) for cordless phones. With regard to benign tumours a somewhat increased risk was found for pleomorphic adenoma, but again based on low numbers.

\section{DISCUSSION}

We found no association between use of cellular or cordless telephones and salivary gland tumours in this study. There was no effect with increasing tumour induction period or number of hours of use of the different phones. However, only six cases had used a phone for more than 10 years, and all of these subjects had used the analogue type. Thus, this study cannot exclude an increased risk among subjects with heavy use for a long time period. The power of the study was to detect an OR $\geqslant 1.4(\alpha=0.05, \beta=0.20)$.

An effect of microwaves would occur during the promotion or progression stage of carcinogenesis. This study was not specifically designed to test a promoting effect or an influence during progression of the tumour. Because odds ratios are an estimate of incidence ratio an effect at these stages will be underestimated by a case-control approach if the factor acts during a comparatively short time.

The parotid gland is within an area with high exposure to microwaves. ${ }^{67}$ For all studied phone types no association was found with tumours in the parotid gland. Furthermore, no consistent pattern of an association was found regarding laterality of phone use and anatomical tumour localisation.

Regarding different tumour types an increased risk was found for squamous cell carcinoma for both cellular (analogue and digital) and cordless telephones. This might be of some interest since both ionising and UV radiation increase the risk for squamous cell carcinoma. ${ }^{14}{ }^{15}$ However, our finding was based on only 13 cases in total, so the result does not permit any conclusions. Skin cancer would be a more suitable tumour type to investigate if an association exists with microwaves. Recently we presented a patient with multiple basal cell carcinomas on the same side of the head as prolonged exposure to microwaves. ${ }^{16}$ Previously we reported a case with angiosarcoma of the scalp and use of a cordless phone. ${ }^{17}$

In a case-control study recall bias can influence the results. Also observational bias can be introduced during the interviews. The questionnaires obtained an ID number that did not indicate if it was a case or a control. All coding of data was done without knowing the subject identity. Furthermore, tumour localisation and type of tumour were assessed without knowledge of exposure data.

In summary our study did not show an association between use of cellular or cordless telephones and salivary gland tumours. However, only a small number of subjects had used such phones for a long period; a longer observation time is needed to exclude an effect on, for example, slowly growing tumours. A somewhat increased risk was found for squamous cell cancer, but this result was based on a small number of cases.

\section{ACKNOWLEDGEMENTS}

This work was supported by grants from Cancer- och Allergifonden, the Swedish Work Environment Fund, Örebro Cancer Fund, and Nyckelfonden. Ms Iréne Larsson, Ms Lena Åkerlund, Mr Matz Ericsson, Dr Freddi Lewin, Dr Claes Mercke, and Dr Jan Lundgren participated in the data collection.

\section{Authors' affiliations \\ L. Hardell, Department of Oncology, University Hospital, SE-701 85 Örebro and Department of Natural Sciences, Orrebro University, SE-701 82 Örebro, Sweden \\ A Hallquist, Department of Oncology-Pathology, Karolinska Institute, The Hospital of Danderyd, SE-182 88 Stockholm, Sweden \\ K Hansson Mild, National Institute for Working Life, SE-907 13 Umeå and Department of Natural Sciences, Örebro University, SE-701 82 Örebro, Sweden \\ M Carlberg, Department of Oncology, University Hospital, SE-701 85 Örebro, Sweden \\ H Gertzén, Department of Otorhinolaryngology, University Hospital, SE-701 85 Örebro, Sweden \\ E-B Schildt, Department of Oncology, University Hospital, S-221 85 Lund, Sweden \\ Å Dahlqvist, Department of Otorhinolaryngology, University Hospital, SE-901 85 Umeå, Sweden}

\section{REFERENCES}

1 Hardell L, Hallquist A, Hansson Mild K, et al. Cellular and cordless telephones and the risk for brain tumours. Eur J Cancer Prev 2002;1 1:377-86.

2 Hardell L, Hansson Mild K, Carlberg M. Case-control study on the use of cellular and cordless phones and the risk for malignant brain tumours. Int J Radiat Biol 2002;78:931-6.

3 Hardell L, Hansson Mild K, Carlberg M. Further aspects on cellular and cordless telephones and brain tumours. Int J Oncol 2003;22:399-407.

4 Hardell L, Hansson Mild K, Sandström M, et al. Vestibular schwannoma, tinnitus and cellular telephones. Neuroepidemiology 2003;22:124-9.

5 Hansson Mild K, Hardell L, Kundi M, et al. Mobile telephones and cancer: is there really no evidence of an association? Int J Mol Med 2003; 12:67-72.

6 Dimbylow PJ, Mann SM. Characterisation of energy deposition in the head from cellular phones. Radiat Protect Dosimetry 1999;83:139-41.

7 Wilén J, Sandström M, Hansson Mild K. Subjective symptoms among mobile phone users - a consequence of absorption of radiofrequency fields. Bioelectromagnetics 2003;24:152-9. 
8 Anon. Cancer incidence in Sweden 2000. Stockholm, Sweden: Centre for Epidemiology, The National Board of Health and Welfare, 2002.

9 Belsky JL, Takeichi N, Yamamoto T, et al. Salivary gland neoplasms following atomic irridation. Cancer 1975:35:555-9.

10 Horn-Ross PL, Ljung BM, Morrow M. Environmental factors and the risk for salivary gland cancer. Epidemiology 1997;8:414-19.

11 Auvinen A, Hietanen M, Luukonen R, Koskela RS. Brain tumours and salivary gland cancers among cellular telephone users. Epidemiology 2002; 13:356-9.

12 Johansen C, Boice JD Jr, McLaughlin JK, et al. Cellular telephones and cancer-a nationwide cohort study in Denmark. J Natl Cancer Inst 2002;93:203-7.
13 Pereiera C, Edwards M. Parotid nodular fasciitis in mobile phone users. $J$ Laryngol Otol 2000; 1 14:886-7.

14 IARC. Monographs on the evaluation of carcinogenic risks to humans. Volume 55. Solar and ultraviolet radiation. Lyon, France: IARC, 1992

15 IARC. Monographs on the evaluation of carcinogenic risks to humans. Volume 75. lonizing radiation, Part 1: X-and gamma $(\gamma)$-radiation, and neutrons. Lyon, France: IARC, 2000.

16 Hardell L, Hansson Mild K, Johansson B. Cellular and cordless telephones and basal cell carcionoma-a case report. Arch Environ Health 2003;58:380-2.

17 Hardell L, Reizenstein J, Johansson B, et al. Angiosarcoma of the scalp and use of a cordless (portable) telephone. Epidemiology 1999;10:785-6. 